\title{
A model of the relationship between consultation behaviour for asthma in a general practice and the weather
}

\author{
Marjan Kljakovic ${ }^{1, *}$, Clare Salmond ${ }^{2}$ \\ ${ }^{1}$ Department of G eneral Practice and 2Department of Public Health, Wellington School of Medicine, M ein Street, N ewtown, \\ Wellington, PO Box 7343, Wellington South, New Zealand
}

\begin{abstract}
The aim of this study was to build a model showing the relationship between consultations for asthma and the daily weather in a suburban computerised general practice in New Zealand. A retrospective count of the number of asthmatic patients attending the practice on any particular day for a consultation for asthma was compared with the weather variables temperature, rainfall, relative humidity, and wind strength. Quasi-likelihood Poisson regression models were built in steps. There were 3844 consultations for asthma between October 1, 1986 and October 30, 1991. The number varied from 0 to 11 consultations per day (mean 2.1). The annual means were 1.3, 1.9, 2.3, 2.5, and 2.7 consultations per day, respectively. After variables indicating time trends, days of the week, and holiday periods were included in the model, temperature and relative humidity provided the only significant additional explanatory power for variation in consultations.
\end{abstract}

KEY WORDS: Asthma $\cdot$ Weather $\cdot$ General practice

\section{INTRODUCTION}

Most published models describing the relationship between consultation patterns for asthma and the climate have been derived from data obtained from Accident and Emergency Departments (Beggs \& Curson 1995). There have been a few observational studies in general practices in England (Ayers et al. 1993, Ayers 1996) and Denmark (Peterson \& Rung Weeke 1981, 1984). These studies have described graphically the influence of the season on patient consultation behaviour for asthma but none examined the short-term effects, such as the relationship between consultation behaviour for asthma and daily weather variables. This retrospective study describes a model for such a relationship.

\footnotetext{
*E-mail: marjan@wnmeds.ac.na
}

\section{METHODS}

\subsection{Clinical data}

The method used for data collection has been described elsewhere (Kljakovic \& Salmond 1996). In summary, data were collected from the only general practice serving a predominantly European middle class population in the suburb of Karori, Wellington city, New Zealand (Information Services Branch 1991). The general practice has computerised its clinical records since 1984 and data on every consultation are entered at the time of encountering the patient. Each registered patient is on an active disease register managed by 8 general practitioners. The practice population remained steady over the period of the study at about 15000 registered patients.

During the study period, 8 general practitioners were responsible for patient care. Routine consultations 
occurred from 08:00 to 18:00 h M onday through Friday, and 08:00 to 12:00 $\mathrm{h}$ on Saturday mornings. The practice provided its own emergency out-of-hours care at all other times.

We used routinely collected data held in the practice clinical database for the study. The following definitions were formulated before extracting the relevant consultation data for analysis.

\subsection{Definitions}

(1) A consultation for asthma. The outcome variable was the count of the number of asthmatic patients attending the practice on any particular day for a consultation for asthma. Each registered patient's clinical record was scrutinised using detailed inclusion criteria (any details of a history suggesting asthma, a diagnosis of asthma, recorded signs of asthma, prescriptions for asthma, and referral for asthma), and exclusion criteria (including patients receiving only repeat prescriptions, recorded consultations where the patient is well, and recorded consultations where patients suffered respiratory tract infections) (Kljakovic \& Salmond 1996).

(2) Reassessment consultation for asthma. Since the purpose of the analyses was to investigate a possible precipitating relationship of the weather to consultations for asthma, follow-up consultation to check or refine symptom relief following an earlier consultation should be excluded. After discussion with the general practitioners involved it appeared that patients were often advised to come back for reassessment in 1, 2, 3d or after $1 \mathrm{wk}$. We therefore defined consultations in the $3 \mathrm{~d}$ after an index consultation, or exactly $7 \mathrm{~d}$ after it, as 'reassessment consultations'.

\subsection{Weather data}

Karori lies in a valley, $600 \mathrm{~m}$ above sea level, and contains about 6000 houses in 1000 ha. The general practice is situated in the centre of the valley and $8 \mathrm{~km}$ from Wellington airport, where daily meteorological data are collected by the New Zealand Meteorological Service. The following daily data were obtained: temperature (to $0.1^{\circ} \mathrm{C}$; average, minimum, maximum), rainfall (to $0.1 \mathrm{~mm}$ ), relative humidity (\%) collected at 09:00 $\mathrm{h}$ every day, and wind strength (average $\mathrm{km} \mathrm{h}^{-1}$ ).

No routine data were available on air pollution or pollen levels.

\subsection{Statistical analysis}

We modelled the number of general practitioner consultations for asthma on each day over the study period. Concurrent weather patterns were the candidate predictors of interest. Covariates and possible confounders included characteristics of the general practice and systematic variation through time.

Since the dependent variable was a count, a quasilikelihood Poisson regression model was fitted, with allowance for possible over-dispersion. Checks confirmed that the assumptions of Poisson regression were appropriate and that slight over-dispersion was present.

The model was built in steps. Firstly, the structural variation in daily attendance caused by the closure of the general practice on Saturday afternoons and Sundays during the period of the study was removed by including dummy variables for day of the week. Secondly, the tendency for attendance to drop on holidays was accounted for by 2 dummy terms for the summerholiday month in J anuary and public holidays. Thirdly, dummy variables for year of study accounted for a nonlinear trend in attendance over the 5 years of the study. Fourthly, annual seasonal variation was filtered by the inclusion of sine and cosine terms with a $1 \mathrm{yr}$ cycle. Other trigonometric functions with shorter cycles did not improve the fit of the model significantly. Shorter term trends in temperature were removed by the inclusion of the average temperature 3 to $7 \mathrm{~d}$ before the day in question. The choice of 3 to $7 \mathrm{~d}$ for characterising short-term trends was made to avoid overlap with the precipitating temperature variables of interest described below.

The final step was to include the daily weather variables, and their delayed effects from the previous $2 \mathrm{~d}$ (as lagged weather variables), to carry the information about the effect of the most recent weather on asthma attendance. A lag structure of up to $2 \mathrm{~d}$ was chosen on the basis that a delay in seeking a consultation will often occur both because a patient may wait for some hours to see if symptom severity changes and because it may take up to a day to arrange a daytime appointment. One and two day lags have also been used in other climate studies (Buchdahl et al. 1996, Holgate 1995). To allow for non-linear weather effects, weather variable distributions were divided into quartiles and the daily weather value was then classified by 2 dummy variables, one each for the highest and lowest quartile. (Using linear effects produced a poorer model.) The final model included effects at lags 1 and 2 , that is, delayed effects from up to $2 \mathrm{~d}$ prior to the day on which the consultation occurred. Sudden changes in temperature have been implicated in the laboratory setting in the onset of asthma symptoms (Ramsey 1977, Strauss et al. 1978, O'Byrne et al. 1982, Zawadski et al. 1988) but no such effect was a significant predictor in our model.

Given the anticipated small overall effect size for the daily weather, there was limited power to detect inter- 


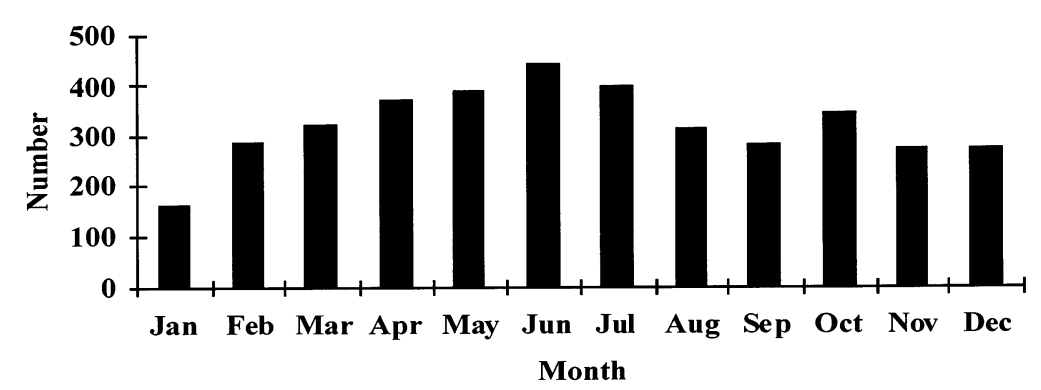

Fig. 1. Number of consultations for asthma $(n=3844)$ for each month in a general practice over $5 \mathrm{yr}$

actions. Only one significant interaction was foundthat between a Sunday and a high maximum temperature the previous day.

M easurements connected in time and space, as here, are likely to be correlated and not independent. This can induce serial correlation in the model residuals. In these circumstances, the model parameter estimates will not be biased, but their standard errors would be. However, our final model yielded statistically significant, but negligible, serial correlation.

The data were entered into an Epi Info (1994) database, checked, and analysed using SAS/INSIGHT (1993).

\section{RESULTS}

There were 3844 consultations for asthma between October 1, 1986 and October 30, 1991, 180 of which were considered to be reassessment consultations within the $3 \mathrm{~d}$ following an index consultation, and 55 of which, also considered reassessment consultations, occurred exactly $7 \mathrm{~d}$ after it.

The number of consultations for asthma per day varied from 0 to 11 (mean 2.1) and increased steadily over the study period (annual means: 1.3, 1.9, 2.3, 2.5, and 2.7 per day, respectively). Consultations were lowest in January and highest in the winter month of June (Fig. 1). Two-fifths of the consultations occurred on either a M onday or Tuesday, the higher rate on those days being partly due to the closure of the practice for most of the weekend (Fig. 2).

The maximum temperature per day varied from 5.8 to $29.0^{\circ} \mathrm{C}$ (median $15.8^{\circ} \mathrm{C}$, upper quartile $18.9^{\circ} \mathrm{C}$ ) while the daily relative humidity varied from 37 to $100 \%$ (median $85 \%$, lower quartile $77 \%$ ). Although Wellington has a reputation as a wet and windy city, no rain fell on more than half of the days, though the median wind strength was $8.5 \mathrm{~km} \mathrm{~h}^{-1}$, the upper quartile was $38.0 \mathrm{~km} \mathrm{~h}^{-1}$, and the max- imum was $94.8 \mathrm{~km} \mathrm{~h}^{-1}$. The largest positive correlation among these weather characteristics was between rainfall and wind or relative humidity (Spearman's rank correlation coefficient 0.30 and 0.24 , respectively); the largest negative rank correlation, -0.15 , was between maximum temperature and relative humidity, the only significant predictors found.

Variables indicating time trends (trigonometric functions of time, year of study), holiday constraints on the population at risk ( anuary, public holiday), and practice access constraints for weekday preferences of patients (day of the week) were all included as significant 'predictors' of daily asthma attendance in our models. (No significant effect of school holidays was observed). Examination of the coefficients (not presented) showed, as expected, that consultations varied with season and increased over the years, particularly after the first, decreased in J anuary and on public holidays, and were particularly high on Mondays and Tuesdays. After these covariates had been entered into the model, temperature and relative humidity provided the only significant additional explanatory power (Table 1 , Model 1). The negative coefficient for the linear term for average temperature 3 to $7 \mathrm{~d}$ earlier shows that lower temperatures imply a higher number of asthma consultations.

The remaining variables in the model refer to the precipitating effect of the weather in the preceding $2 \mathrm{~d}$. A relatively low relative humidity (in the lowest quartile) $2 \mathrm{~d}$ before and a relatively high maximum temperature (in the upper quartile) the day before both decreased the probability of a consultation for asthma. The influence of temperature on attendance, however, was ameliorated on Sundays (interaction term positive), presumably because the constraint that the practice was closed at the weekend is already accounted for in the model.

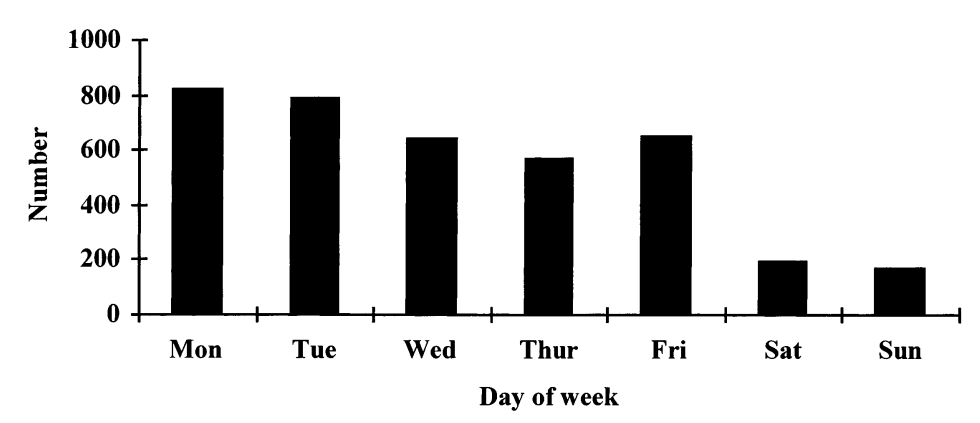

Fig. 2. Number of consultations for asthma $(n=3844)$ for each day of week in a general practice over $5 \mathrm{yr}$ 
Table 1. Multivariate regression models between the daily number of consultations for asthma and the weather in a general practice in Wellington, New Zealand, 1986-1991. Model 1 includes the following variables (not shown) as covariates: year of study, day of week (dummy variables with references 1991 and Wednesday); sine and cosine functions of time with a period of 1 yr; dummy variables indicating $\mathrm{J}$ anuary and public holiday. The dependent variable is the daily count of all consultations for asthma. Model 2 includes the same covariates as Model 1 but the dependent variable is the number of consultations for asthma excluding 235 reassessment consultations (out of a total of 3844). Rate ratio for average temperature 3 to $7 \mathrm{~d}$ before the consultation is calculated for an increase of $1^{\circ} \mathrm{C}$. $\mathrm{Cl}$ : confidence interval. p-value is for chi-square (Wald test)

\begin{tabular}{|c|c|c|c|c|c|c|}
\hline Variable & Rate ratio & $\begin{array}{l}\text { Model } 1 \\
95 \% \mathrm{Cl}\end{array}$ & $p$-value & Rate ratio & $\begin{array}{l}\text { Model } 2 \\
95 \% \mathrm{Cl}\end{array}$ & $p$-value \\
\hline $\begin{array}{l}\text { Relative humidity in lowest quartile } \\
2 \mathrm{~d} \text { before consultation }\end{array}$ & 0.91 & $0.84-0.99$ & 0.028 & 0.91 & $0.84-0.99$ & 0.035 \\
\hline $\begin{array}{l}\text { Maximum temperature in highest } \\
\text { quartile } 1 \mathrm{~d} \text { before consultation }\end{array}$ & 0.85 & $0.76-0.95$ & 0.006 & 0.85 & $0.76-0.95$ & 0.005 \\
\hline $\begin{array}{l}\text { Maximum temperature as above on } \\
\text { Sundays (interaction term) }\end{array}$ & 1.62 & $1.12-2.34$ & 0.011 & 1.61 & $1.10-2.35$ & 0.014 \\
\hline $\begin{array}{l}\text { Average temperature } 3 \text { to } 7 d \\
\text { before consultation }\end{array}$ & 0.98 & $0.95-1.00$ & 0.039 & 0.98 & $0.95-1.00$ & 0.039 \\
\hline
\end{tabular}

No other weather terms were found that contributed significantly to explaining attendance variation. They included dummy variables representing the upper and lower quartiles of all the temperature, relative humidity, wind strength, and rainfall data for the index day and each of the previous 2 days, as well as change in temperature over the preceding 24,48 and $72 \mathrm{~h}$. Interactions between these variables were also examined.

The underlying assumptions of the statistical model were examined. The (deviance) residuals showed significant non-zero serial correlation at lags 1 and 7 (0.089 and 0.078 , respectively) but these are sufficiently small to have a negligible effect on the overall results.

An analysis excluding the estimated reassessment consultations, that is, consultations prompted by the general practitioners rather than precipitated by the weather (Table 1, Model 2), gave substantively similar results to the analysis for all consultations, but with slightly smaller levels of serial correlation. These were again only significant for lags 1 and 7 (0.066 and 0.070).

\section{DISC USSION}

This study demonstrates that modelling the relationship between consultation behaviour and weather is possible in the general practice setting. From an environmental health point of view, it is important to understand which weather factors influence patient consultation behaviour over a wide range of health service settings (Beggs \& Curson). Our model showed that, after including a set of variables sufficient to address the delays between weather exposure and consultation, yearly cyclic variation due to the seasons, and the time series nature of the data, the most important characteristics associated with attendance at a general practice were temperature and relative humidity.

There are both short-term and long-term time trends in the occurrence of asthmatic consultations (Pedersen \& Rung Weeke 1984, Ayers et al. 1993). We have demonstrated short-term fluctuations in consultations for asthma and the lag effects of the weather variables occurring up to $2 \mathrm{~d}$ prior to the day of consultation. Other studies in Accident and Emergency Department settings have demonstrated a lag effect for temperature and humidity (Salvaggio et al. 1970). In this study the long-term change in asthmatic consultations over the 5 years of study was seen particularly after the first year. A similar increase over long time periods has been demonstrated in general practice in the United Kingdom (Ayers J G 1986) and in Accident and Emergency Department attendance in $\mathrm{New}$ Zealand (Mitchell \& Cutler 1984). This long-term increase may reflect a rise in workload (for example, altered funding arrangements influence consultation trends) and not necessarily an increase in the frequency or severity of acute asthmatic attacks. There have been no general practice based studies which specifically study the tendency of patients to consult in response to acute symptoms (Holgate 1995).

A few New Zealand studies have linked the weather with consultations for asthma in outpatient hospital clinics (Beasley et al. 1988, Bruce 1989) and the Accident and Emergency Department (Dawson \& Allan 1983). Such patients, however, represent the most severe and most acute episodes of asthma. Patients attending general practice have both severe and mild forms of asthma as opposed to those attending the Accident and Emergency Department (Kljakovic \& 
Stuart 1996) and therefore warrant a specific research focus. In New Zealand less than $1 \%$ of patients attending general practice in a year have serious asthma needing hospital attention (Kljakovic 1994, M cAvoy et al. 1994). Community based studies show that 1 in 8 New Zealanders have been told at some time by a doctor that they have asthma (Triggs et al. 1994). It is important to understand how local weather patterns influence asthma attendance in general practice so that asthma management plans might include specific advice to adjust medication according to the local weather.

\section{LITERATURE CITED}

Ayers J G (1986) Trends in asthma and hay fever in general practice in the United Kingdom 1976-83. Thorax 41: 111-116

Ayers J G, Noah ND, Fleming DM (1993) Incidence of episodes of acute asthma and acute bronchitis in general practice 1976-87. Br J Gen Prac 43(374):361-364

Beasley R, Coleman ED, Hermon Y, Holst PE, O'Donnel TV, Tobias M (1988) Viral respiratory tract infection and exacerbations of asthma in adult patients. Thorax 43:679-683

Beggs PJ, Curson PH (1995) An integrated environmental asthma model. [Review]. Arch Environ Health 50(2):87-94

Bruce P (1989) Asthma and weather: relationship of weather and asthma attacks in Wellington. Weather Clim 9:15-22

Buchdahl R, Parker A, Stebbings T, Babiker A (1996) A ssociation between air pollution and acute childhood wheezy episodes: prospective observational study. $\mathrm{Br} \mathrm{Med} J \mathrm{J12}$ 661-665

Dawson KP, Allan J , Fergusson DM (1983) Asthma, air pollution and climate: a Christchurch study. NZ Med J 96(727): 165-167

Epi Info (1994) Version 6. Centers for Disease Control and Prevention, Atlanta

Holgate ST (ed) (1995) Asthma and outdoor air pollution. HMSO, London

Information Services Branch (1992) 1991 census of population and dwellings. Wellington Regional Report. Department of Statistics, Wellington

Editorial responsibility: Laurence Kalkstein,

Newark, Delaware, USA
Kljakovic M (1994) A comparison of the respiratory care given to asthmatic and non asthmatic children in a general practice. NZ Med J 107:240-242

Kljakovic M, Salmond C (1996) The pattern of consultations for asthma in a general practice over five years. NZ M ed J 109:48-50

Kljakovic M, Stuart D (1996) Out-of-hours attendance and outcomes for asthmatic patients at two primary care services. NZ Med J 109:254-257

McAvoy B, Davis P, Raymont A, Gribben B (1994) The Waikato Medical Care (WaiMedCa) Survey 1991-1992. NZ Med J 107(986 Pt 2):388-433

Mitchell EA, Cutler DR (1984) Paediatric admissions to Auckland Hospital for asthma from 1970-1980. NZ Med J 97: 67-70

O'Byrne PM, Ryan G, Morris M, McCormack D, J ones NL, M orse J LC, Hargreave FE (1982) Asthma induced by cold air and its relation to nonspecific bronchial responsiveness to methalcholine. Am Rev Respir Dis 125:281-285

Pedersen PA, Rung Weeke E (1981) Asthma in Danish general practice. Prevalence and consultation rates. Allergy 36(3): 175-181

Pedersen PA, Rung Weeke E (1984) Seasonal variation of asthma and allergic rhinitis. Consultation pattern in general practice related to pollen and spore counts and to five indicators of air pollution. Allergy 39(3):165-170

Ramsey JM (1977) Time course of bronchoconstrictive response in asthmatic subjects to reduced temperature. Thorax 32:26-28

Salvaggio J , Hasselbad V, Seabury J , Heiderscheid LT (1970) New Orleans asthma II, Relationship of climatologic and seasonal factors to outbreaks. J Allergy 45:257-265

SAS/INSIGHT (1993) User's guide. Version 6. SAS Institute Inc, Cary, NC

Strauss RH, M cFadden ER, Ingram RH, Deal CE, J aeger J J , Stearns D (1978) Influence of heat and humidity on the airway obstruction induced by exercise in asthma. J Clin Invest 61:433-440

Triggs S, O'C onnor P, Turner S (1994) Four in ten. A profile of New Zealanders with a disability or long term illness. Ministry of Health, Wellington

Zawadski DK, Lenner KA, M cFadden ER (1988) Comparison of intra-airways temperatures in normal and asthmatic subjects after hypernea with hot, cold, and ambient air Am Rev Respir Dis 138:1553-1558

Submitted: December 22, 1997; Accepted: J une 16, 1998

Proofs received from author(s): August 7, 1998 